\title{
Optimasi Capacitated Vehicle Routing Problem with Time Windows dengan Menggunakan Ant Colony Optimization
}

\author{
Iwan Aang Soenandi ${ }^{*}$, Joice, Budi Marpaung \\ Program Studi Teknik Industri, Fakultas Teknik dan Ilmu Komputer, Universitas Kristen Krida Wacana, Jalan Tanjung Duren
} Raya No 4, Jakarta, Jakarta Barat Indonesia

\section{ARTICLE INFORMATION}

Article history:

Received: June 11, 2019

Revised: July 22, 2019

Accepted: July 30, 2019

\section{Kata Kunci:}

Ant Colony Optimization

Capacitated Vehicle Routing with Time Windows

Optimasi

Vehicle Routing Problem

\section{Keywords:}

Ant Colony Optimization

Capacitated Vehicle Routing with Time

Windows

Optimization

Vehicle Routing Problem

${ }^{*}$ Corresponding Author

Iwan Aang Soenandi

E-mail: iwan.as@ukrida.ac.id

\section{A B S T R A K}

Beberapa tahun terakhir ini, minimisasi biaya logistik dan transportasi menjad hal yang penting pada perusahaan manufaktur untuk meningkatkan profit. Salah satu hal yang dilakukan untuk mengurangi biaya logistik dan transportasi adalah dengan cara mengoptimalkan rute pengambilan atau pengangkutan komponen dari setiap supplier. Pengoptimalan rute dengan tujuan untuk meminimalkan total biaya transportasi merupakan permasalahan yang sering ditemukan pada Vehicle Routing Problem (VRP). Problem Capacitated Vehicle Routing with Time Windows (CVRPTW) merupakan salah satu varian dari VRP yang mempertimbangkan kapasitas kendaraan dan jangka waktu pelayanan tiap kendaraan. CVRPTW merupakan permasalahan Non- Polynomial Hard (NP-Hard) yang memerlukan algoritma yang efisien dan efektif dalam menyelesaikan permasalahan yang terjadi di perusahaan otomotif ini. Penelitian ini menggunakan algoritma Ant Colony Optimization (ACO) dengan pengujian menggunakan beberapa parameter untuk menyelesaikan permasalahan CVRPTW. Hasil pengujian menggunakan algoritma ACO diperoleh rute yang lebih cepat dibandingkan dengan metode yang diterapkan perusahaan.

\section{A B S T R A C T}

In recent years, minimization of logistics and transportation costs has become essential for manufacturing companies to increase profits. One thing is done to reduce logistics and transportation costs by optimizing the route of taking or transporting components from each supplier. Route optimization to minimize total transportation costs is a problem that often finds in Vehicle Routing Problems (VRP). Problem Capacitated Vehicle Routing with Time Windows (CVRPTW) is one variant of VRP that considers the vehicle capacity and the service period of each vehicle. CVRPTW is a Non-Polynomial Hard (NP-Hard) problem that requires an efficient and effective algorithm in solving problems that occur in this automotive company. This study uses the Ant Colony Optimization (ACO) algorithm by testing using several parameters to solve the CVRPTW problem. The test results using the ACO algorithm obtained a faster route compared to the method applied by the company.

This is an open access article under the CC-BY-NC-SA license.

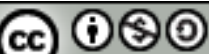

\section{PENDAHULUAN}

Saat ini, semua perusahaan modern selalu mencari cara untuk dapat mengoptimalkan proses logistik dan distribusi dalam pemenuhan kebutuhan setiap konsumen yang beragam [1]. Pada sebagian besar industri, biaya transportasi merupakan salah satu penyumbang biaya terbesar dalam biaya logistik, berada pada kisaran 10 hingga 25 persen dari total biaya perusahaan [2]. Dengan pengaruh yang signifikan tersebut, perusahaan logistik dapat mencapai keuntungan besar. Optimasi rute dan jadwal pada aktivitasnya dengan cara 
memaksimalkan kapasitas dan optimasi rute pengangkutan komponen akan secara signifikan mengurangi biaya transportasi [3], [4]. Secara umum, keuntungan perusahaan logistik bergantung pada utilitas kendaraan, tingkat pelayanan yang tinggi, pengurangan biaya transportasi, pengurangan investasi capital di penyediaan peralatan, dan manajemen pengambilan keputusan yang lebih baik [5], [6].

Berdasarkan hasil observasi di lapangan, industri otomotif umumnya menggunakan pengiriman milk-run untuk mendatangkan komponen dari supplier yang biasanya berjumlah banyak. Tujuan milk-run adalah untuk meminimumkan biaya persediaan dan biaya transportasi. Biaya pengadaan komponen sangat berpengaruh pada total biaya yang dikeluarkan perusahaan seperti pada industri mobil [7]. Permasalahan penentuan rute kendaraan dengan milk-run merupakan varian dari permasalahan Vehicle Routing Problem (VRP). VRP dapat dideskripsikan sebagai permasalahan mendesain rute pengiriman/pengumpulan yang optimal atau rute pengumpulan dari satu atau beberapa depot ke beberapa supplier yang lokasinya tersebar secara geografis dengan memenuhi kendala yang ada. VRP memiliki peran penting dalam distribusi fisik dan logistik. VRP fokus menemukan satu set rute kendaraan yang berangkat dan kembali ke depot, dimana rute melingkupi satu set pelanggan. Setiap pelanggan memiliki permintaan yang berbeda dan sekali perjalanan satu set rute dibatasi oleh kapasitas kendaraan [8].

Penelitian ini mengangkat suatu kasus di sebuah perusahaan otomotif yang memproduksi mobil dengan model dan varian yang beragam di daerah Cibitung. Beragamnya jenis komponen membuat perusahaan memiliki lebih dari 250 supplier yang tersebar luas di beberapa kota. Sebanyak $60 \%$ supplier berada dalam jarak 50 $\mathrm{km}$ dari lokasi perusahaan, dan $40 \%$ berada lebih dari $50 \mathrm{~km}$. Dengan menggunakan sistem milk-run, perusahaan bekerjasama dengan third party logistic (TPL) untuk pengambilan komponen dari setiap supplier. Perusahaan tidak menyediakan kendaraan sendiri untuk mendatangkan komponen dari supplier. Hingga saat ini penentuan rute milk-run untuk pengambilan komponen dari setiap supplier belum pernah diperiksa optimalisasinya. Dalam hal ini, bisa saja setelah melakukan optimalitas terhadap rute milk-run jarak tempuh yang diperoleh lebih baik dari sebelumnya. Permasalahan lain yang dihadapi yaitu keterlambatan kedatangan kendaraan pembawa komponen yang mengakibatkan lini produksi berhenti dan secara tidak langsung berdampak pada biaya produksi. Dalam hal ini, perusahaan sudah menerapkan sistem JIT (just in time) untuk mendukung proses produksinya, dimana komponen dipesan $\mathrm{H}-1$ dan kemudian akan digunakan pada hari berikutnya. Hal ini menyebabkan setiap kendaraan pembawa komponen harus tiba di depot tepat waktu.

Salah satu metode yang biasa digunakan dalam optimasi pengiriman adalah Ant Colony Optimization (ACO). Gagasan ACO meniru jejak feromon yang digunakan oleh semut untuk menemukan jejak terdekat antara sarang dengan sumber makanan [9]. Jalur feromon di ACO berfungsi sebagai informasi numerik yang digunakan oleh semut untuk secara probabilistik membangun solusi untuk masalah yang sedang dipecahkan dan beradaptasi selama eksekusi algoritma yang mencerminkan pengalaman pencarian mereka [10]. Beberapa penelitian telah membuktikan ACO sebagai algoritma yang efisien untuk memecahkan masalah optimisasi rute kendaraan [11], [12], dan [13].

Penelitian ini bertujuan untuk mengoptimalkan rute kendaraan yang dibutuhkan untuk melayani semua supplier dan penjadwalan pengambilan komponen dengan mempertimbangkan kendala kapasitas kendaraan dan waktu. Kendala kapasitas kendaraan dimaksudkan untuk memberi batasan dalam pembentukan rute dari supplier yang dikunjungi. Jika muatan kendaraan sudah penuh maka akan kembali ke depot, dan kendaraan berikutnya akan membentuk rute dari supplier yang berbeda. Sementara kendala waktu dimaksudkan untuk rentang waktu pengambilan komponen dari supplier sehingga tiba di depot sesuai dengan jadwal yang telah ditentukan. Asumsi dalam penelitian ini adalah, hanya terdapat satu jenis kendaraan yang digunakan untuk pengangkutan barang dan dalam penentuan rute, jumlah kendaraan, dan jadwal kedatangan kendaraan hanya untuk satu siklus pengiriman (single-trip). Hasil pendekataan pencarian rute optimal diharapkan dapat mengurangi jarak tempuh pengambilan komponen dari setiap supplier sehingga berpengaruh terhadap biaya transportasi.

\section{METODE PENELITIAN}

Penelitian ini dilakukan di sebuah perusahaan otomotif di daerah Cibitung, Jawa Barat. Penelitian merancang rute optimal untuk armada kendaraan dalam pengambilan komponen dari setiap supplier dengan pembatasan Time 
Windows. Vehicle Routing Problem with Time Windows (VRPTW) yang merupakan generalisasi dari VRP yang melayani pelanggan dalam rentang waktu yang diberikan [14], [15]. Penyelesaian permasalahan optimasi VRP dengan metode ACO pada penelitian ini dibuat pada software MATLAB untuk memudahkan pencarian rute optimal.

\section{Ant Colony Optimization}

Pada awal 1990-an, Ant Colony Optimization (ACO) diperkenalkan oleh M. Dorigo dan rekannya sebagai sebuah metode baru dalam pendekatan metaheuristik yang terinspirasi dari alam untuk permasalahan optimasi kombinatorial [16], Sumber inspirasi terbentuknya ACO adalah dari kehidupan nyata perilaku semut mencari makanan. Ketika mencari makanan, semut awalnya menjelajahi daerah sekitar sarang secara acak dan akan kembali ke sarangnya dengan membawa makanan. Selama perjalanan kembali ke sarang, semut menyimpan atau meninggalkan jejak berupa zat feromon di tanah pada jalur yang dilaluinya. Komunikasi secara tidak langsung terjadi antara semut dan jalur dari zat feromon yang memungkinkan para semut menemukan jalur terpendek antara sumber sarang dan sumber makanan [17], [18], [19], dan [20]. Semakin sering dan pendek jalur yang dilalui oleh semut maka semakin kuat pula zat feromon, yang kemudian akan memandu semut lain untuk melalui jalur tersebut. Karakteristik dari koloni semut nyata dalam mencari makanan kemudian dieksploitasi ke dalam koloni semut buatan untuk memecahkan masalah optimasi kombinatorial [21], [22].

Penelitian ini akan merancang rute optimal untuk sistem milk-run di perusahaan dalam pengambilan komponen di setiap supplier. Penelitian ini berfokus pada VRP dengan mempertimbangkan kendala kapasitas dan rentang waktu dalam pengangkutan komponen dari setiap supplier. Penelitian ini juga mempertimbangkan jarak dan/atau waktu sebagai dasar optimasi dengan melihat hubungan keduanya. Permasalahan CVRPTW akan menggunakan metode ACO dalam penyelesaiannya seperti yang terlihat pada flowchart di Gambar 1, berdasarkan informasi dari beberapa penelitian sebelumnya bahwa metode ACO merupakan salah satu metode yang dapat memberikan solusi mendekati optimal dengan waktu komputasi relatif pendek. Sepanjang pengetahuan penulis, penelitian ini merupakan penelitian pertama tentang VRP yang mempertimbangkan kendala kapasitas dan jendela waktu secara simultan pada industri otomotif dengan memilih metode penyelesaian masalah menggunakan metode ACO.

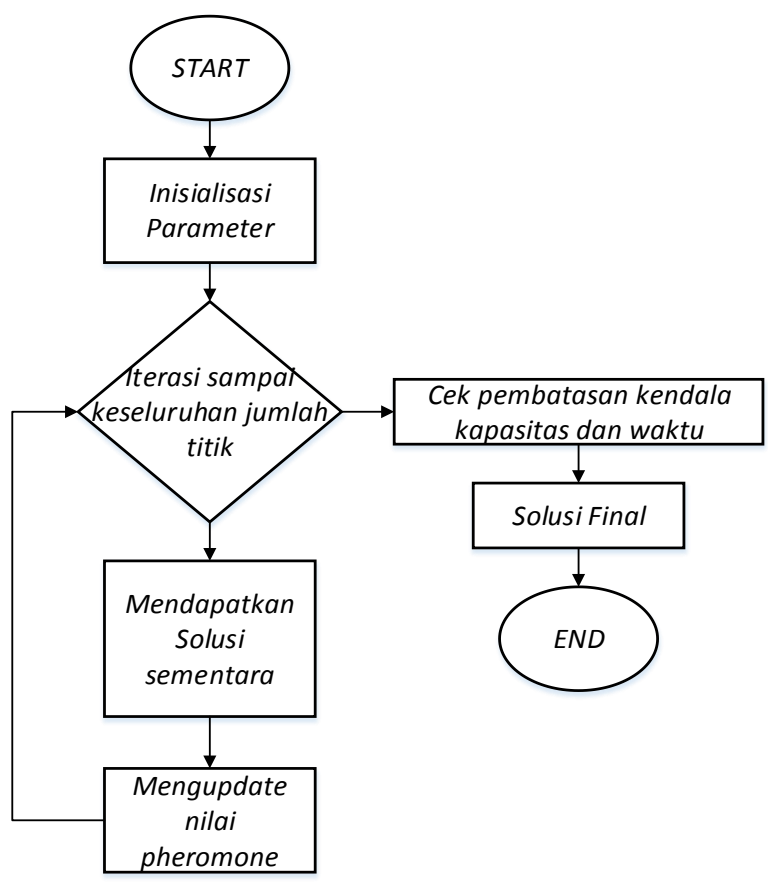

Gambar 1. Flowchart dari algoritma ACO

\section{HASIL DAN PEMBAHASAN}

Pada program ACO menggunakan software MATLAB, pencarian rute optimal akan di run sebanyak lima kali, dipilih rute dan jarak yang paling optima, kemudian diolah lagi secara manual dengan mempertimbangkan kendala kapasitas dan rentang waktu. Pada cluster Cibitung terdapat 22 supplier yang bekerjasama dengan perusahaan untuk memenuhi kebutuhan produksi kendaraan roda empat. Setiap supplier sudah ditentukan jumlah permintaannya, dengan kapasitas kendaraan $24 \mathrm{~m}^{3}$. Oleh karena itu setiap supplier yang kapasitasnya lebih besar dari kapasitas kendaraan maka direkomendasikan untuk melakukan pengiriman secara langsung.

Pada penyelesaian permasalahan VRP menggunakan metode ACO, nilai parameter yang digunakan mengikuti penelitian Huang et al. (2018), yaitu koefisien evaporasi $=0.2$, alpha $=4$, beta $=4$, dan koefisien eliminasi $=0.96$, dimana telah dilakukan uji coba terhadap nilai parameternya dan terbukti hasilnya lebih baik. Sedangkan jumlah semut yang digunakan sebanyak 100 semut dengan literasi sebanyak 500. 


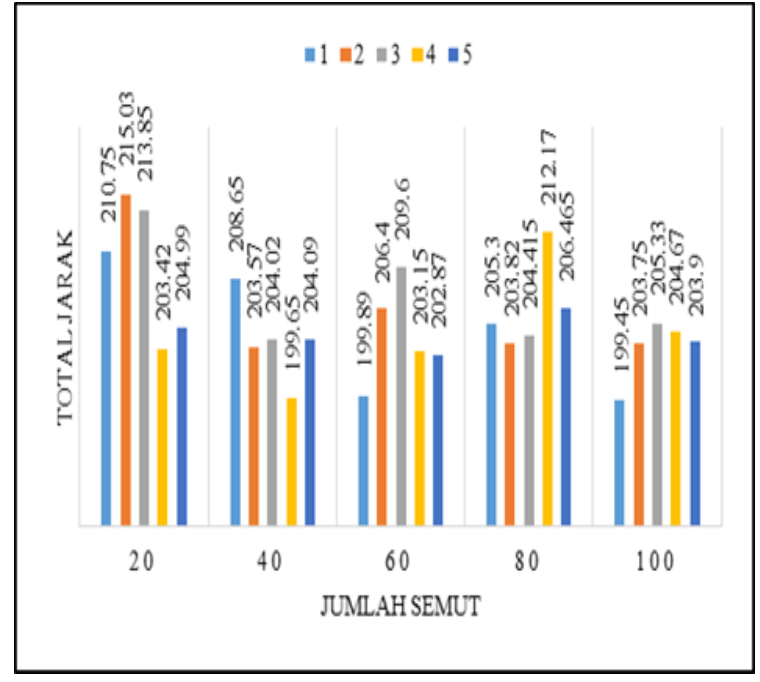

Gambar 2. Grafik perbandingan optimasi ACO berdasarkan jumlah semut

Pada penentuan jumlah semut dilakukan perbandingan solusi minimum dengan lima kali percobaan. Adapun jumlah semut yang dibandingkan adalah 20, 40, 60, 80 dan 100 semut. Hasil yang didapatkan untuk 20 semut dapat menemukan solusi minimum sebesar 203.42; 40 semut dapat menemukan solusi minimum sebesar 199.65; 60 semut dapat menemukan solusi minimum sebesar 199.89; 80 semut dapat menemukan solusi minimum sebesar 203.82; dan 100 semut dapat menemukan solusi minimum sebesar 199.45. Dengan demikian jumlah semut 100 adalah yang terbaik untuk digunakan sebagai parameter untuk menyelesaikan permasalahan VRP karena memiliki solusi yang paling minimum dari percobaan yang telah dilakukan. Pada Gambar 2 dapat dilihat grafik perbandingan jumlah semut yang digunakan.
Berdasarkan hasil pengolahan dengan metode ACO terbentuk lima rute milk-run yang optimal pada cluster Cibitung dengan mempertimbangkan kendala kapasitas kendaraan dan jendela waktu. Adapun lima rute yang terbentuk pada cluster Cibitung diuraikan sebagai berikut:

a. Rute 1 (0-7-3-5-21-0) dengan jarak tempuh kendaraan $90.4 \mathrm{~km}$ dan efisiensi muatan kendaraan $96.28 \%$ (Tabel 1).

b. Rute 2 (0-6-15-9-2-8-0) dengan jarak tempuh kendaraan $102.3 \mathrm{~km}$ dan efisiensi muatan kendaraan $99.12 \%$ (Tabel 2).

c. Rute 3 (0-4-10-22-17-20-0) dengan jarak tempuh kendaraan $148.3 \mathrm{~km}$ dan efisiensi muatan kendaraan $97.11 \%$ (Tabel 3).

d. Rute 4 (0-12-11-19-0) dengan jarak tempuh kendaraan $96.85 \mathrm{~km}$ dan efisiensi muatan kendaraan $96.33 \%$ (Tabel 4).

e. Rute 5 (0-16-14-18-13-0) dengan jarak tempuh kendaraan $197.5 \mathrm{~km}$ dan efisiensi muatan kendaraan $81.82 \%$ (Tabel 5).

Adapun jadwal kedatangan dan keberangkatan kendaraan dari setiap supplier ditentukan berdasarkan waktu tempuh antara supplier, proses loading-unloading komponen dan waktu yang ditempuh untuk kembali ke depot. Berdasarkan wawancara dengan pihak perusahaan, proses loading-unloading komponen membutuhkan waktu rata-rata 30 menit. Dengan demikian pengambilan komponen dari setiap supplier dilakukan dalam rentang waktu selama 30 menit. Batas waktu setiap kendaraan dalam pengambilan komponen pada supplier sesuai dengan rute yang dilalui yaitu pukul 05.00 WIB. Setiap kendaraan harus tiba di depot tepat pukul 06.30 WIB. Adapun waktu rata-rata perjalanan dari supplier ke depot adalah 90 menit. Dengan demikian diharapkan bahwa setiap kendaraan tiba di depot tepat waktu.

Tabel 1. Analisa waktu dan kapasitas rute 1

\begin{tabular}{|c|c|c|c|c|c|c|}
\hline \multicolumn{7}{|c|}{ Rute $1(0-7-3-5-21-0)$ Jarak $=90.4 \mathrm{~km}$} \\
\hline Lokasi & Waktu & Ket. & $\begin{array}{l}\text { Volume } \\
\text { (m3) }\end{array}$ & $\begin{array}{c}\text { Volume Kum. } \\
\text { (m3) }\end{array}$ & Ket. & $\begin{array}{c}\text { Efisiensi } \\
(\%)\end{array}$ \\
\hline \multirow{2}{*}{7} & 2.40 & Tiba & \multirow[t]{2}{*}{10.68} & \multirow[t]{2}{*}{10.68} & \multirow{2}{*}{ Lanjut } & \multirow{8}{*}{96.28} \\
\hline & 3.10 & Selesai & & & & \\
\hline \multirow{2}{*}{3} & 3.20 & Tiba & 2.06 & 12.74 & Lanjut & \\
\hline & 3.50 & Selesai & \multirow{3}{*}{6.03} & \multirow{3}{*}{18.77} & \multirow{3}{*}{ Lanjut } & \\
\hline \multirow[t]{2}{*}{5} & 3.55 & Tiba & & & & \\
\hline & 4.25 & Selesai & & & & \\
\hline \multirow{2}{*}{21} & 4.30 & Tiba & \multirow{2}{*}{4.34} & \multirow{2}{*}{23.11} & \multirow{2}{*}{$\begin{array}{l}\text { Menuju } \\
\text { depot }\end{array}$} & \\
\hline & 5.00 & Selesai & & & & \\
\hline
\end{tabular}


Tabel 2. Analisa waktu dan kapasitas rute 2

\begin{tabular}{|c|c|c|c|c|c|c|}
\hline \multicolumn{7}{|c|}{ Rute 2 (0-6-15-9-2-8-0) Jarak =102.3km } \\
\hline Lokasi & Waktu & Ket. & $\begin{array}{l}\text { Volume } \\
\text { (m3) }\end{array}$ & $\begin{array}{c}\text { Volume } \\
\text { Kum.(m3) }\end{array}$ & Ket. & Efisiensi(\%) \\
\hline 6 & $\begin{array}{l}1.50 \\
2.20\end{array}$ & $\begin{array}{c}\text { Tiba } \\
\text { Selesai }\end{array}$ & 6.68 & 6.68 & Lanjut & \\
\hline 15 & $\begin{array}{l}2.30 \\
2.50\end{array}$ & $\begin{array}{c}\text { Tiba } \\
\text { Selesai }\end{array}$ & 0.51 & 7.19 & Lanjut & \\
\hline 9 & $\begin{array}{l}3.05 \\
3.35 \\
\end{array}$ & $\begin{array}{c}\text { Tiba } \\
\text { Selesai }\end{array}$ & 0.88 & 8.07 & Lanjut & 94.96 \\
\hline 2 & $\begin{array}{l}3.45 \\
4.15 \\
\end{array}$ & $\begin{array}{c}\text { Tiba } \\
\text { Selesai }\end{array}$ & 13.32 & 21.39 & Lanjut & \\
\hline 8 & $\begin{array}{l}4.30 \\
5.00\end{array}$ & $\begin{array}{l}\text { Tiba } \\
\text { Selesai }\end{array}$ & 1.4 & 22.79 & $\begin{array}{c}\text { Menuju } \\
\text { depot }\end{array}$ & \\
\hline
\end{tabular}

Tabel 3. Analisa waktu dan kapasitas rute 3

\begin{tabular}{|c|c|c|c|c|c|c|}
\hline \multicolumn{7}{|c|}{ Rute $3(0-4-10-22-17-20-0)$ Jarak $=148.3 \mathrm{~km}$} \\
\hline Lokasi & Waktu & Ket. & $\begin{array}{l}\text { Volume } \\
\text { (m3) }\end{array}$ & $\begin{array}{l}\text { Volume Kum. } \\
\qquad(\mathrm{m} 3)\end{array}$ & Ket. & $\begin{array}{l}\text { Efisiensi } \\
\text { (\%) }\end{array}$ \\
\hline \multirow{2}{*}{4} & 1.20 & Tiba & \multirow{2}{*}{1.06} & \multirow{2}{*}{1.06} & \multirow{2}{*}{ Lanjut } & \multirow{9}{*}{97.11} \\
\hline & 1.50 & Selesai & & & & \\
\hline \multirow{2}{*}{10} & 1.55 & Tiba & \multirow{2}{*}{4.09} & \multirow{2}{*}{5.15} & \multirow{2}{*}{ Lanjut } & \\
\hline & 2.25 & Selesai & & & & \\
\hline \multirow{2}{*}{22} & 2.30 & Tiba & \multirow{2}{*}{2.1} & \multirow{2}{*}{7.25} & \multirow{2}{*}{ Lanjut } & \\
\hline & 3.00 & Selesai & & & & \\
\hline \multirow{2}{*}{17} & 3.25 & Tiba & \multirow{2}{*}{2.89} & \multirow{2}{*}{10.14} & \multirow{2}{*}{ Lanjut } & \\
\hline & 3.55 & Selesai & & & & \\
\hline 20 & $\begin{array}{l}4.30 \\
5.00\end{array}$ & $\begin{array}{l}\text { Tiba } \\
\text { Selesai }\end{array}$ & 13.17 & 23.31 & $\begin{array}{c}\text { Menuju } \\
\text { depot }\end{array}$ & \\
\hline
\end{tabular}

Tabel 4. Analisa waktu dan kapasitas rute 4

\begin{tabular}{ccccccc}
\hline \multicolumn{7}{c}{ Rute 4 } \\
\hline Lokasi & Waktu & Ket. & $\begin{array}{c}\text { Volume } \\
(\mathrm{m} 3)\end{array}$ & $\begin{array}{c}\text { Volume } \\
\text { Kum. }(\mathrm{m} 3)\end{array}$ & Ket. & $\begin{array}{c}\text { Efisiensi } \\
(\%)\end{array}$ \\
\hline 12 & 2.50 & Tiba & 1.45 & 1.45 & Lanjut & \\
& 3.20 & Selesai & & & Lanjut & 96.33 \\
11 & 3.45 & Tiba & 11.31 & 12.76 & & \\
& 4.15 & Selesai & & Menuju & \\
& 4.30 & Tiba & 10.36 & 23.12 & depot & \\
\hline
\end{tabular}


Tabel 5. Analisa waktu dan kapasitas rute 5

\begin{tabular}{|c|c|c|c|c|c|c|}
\hline \multicolumn{7}{|c|}{ Rute $5(0-16-14-18-13-0)$ Jarak $=197.5 \mathrm{~km}$} \\
\hline Lokasi & Waktu & Ket. & $\begin{array}{l}\text { Volume } \\
\text { (m3) }\end{array}$ & $\begin{array}{c}\text { Volume } \\
\text { Kum. } \\
\text { (m3) }\end{array}$ & Ket. & $\begin{array}{c}\text { Efisiensi } \\
(\%)\end{array}$ \\
\hline \multirow{2}{*}{16} & 24.15 & Tiba & \multirow{2}{*}{5.12} & \multirow{2}{*}{5.12} & \multirow{2}{*}{ Lanjut } & \multirow{8}{*}{81.82} \\
\hline & 24.45 & Selesai & & & & \\
\hline \multirow{2}{*}{14} & 1.45 & Tiba & 362 & 874 & I aniut & \\
\hline & 2.05 & Selesai & & & & \\
\hline \multirow{2}{*}{18} & 3.40 & Tiba & \multirow{2}{*}{4.65} & \multirow{2}{*}{13.39} & \multirow{2}{*}{ Lanjut } & \\
\hline & 4.10 & Selesai & & & & \\
\hline \multirow{2}{*}{13} & 4.30 & Tiba & \multirow{2}{*}{6.25} & \multirow{2}{*}{19.64} & \multirow{2}{*}{ Menuju depot } & \\
\hline & 5.00 & Selesai & & & & \\
\hline
\end{tabular}

Dari hasil analisa waktu kapasitas seperti yang dapat dilihat pada Tabel 1-5, semuanya memenuhi batasan waktu dan kapasitas truk. Dari perbandingan rute hasil temuan dan rute existing, secara keseluruhan selisih jarak tempuh yang diperoleh yaitu $36 \mathrm{~km}$. Dengan demikian rute hasil temuan lebih baik dari rute existing karena dapat mengurangi jarak tempuh sebanyak $36 \mathrm{~km} /$ hari. Dengan demikian terjadi penghematan sebanyak $9000 \mathrm{~km} / \mathrm{tahun}$ (250 hari kerja). Jika jarak tempuh berkurang maka dampaknya biaya transportasi juga akan berkurang. Penghematan ini masih ditambah dengan kepastian jadwal pengiriman barang sehingga tidak terjadi gangguan produksi karena keterlambatan pengiriman barang. Hasil penelitian ini selaras dengan penelitian sebelumnya yang mengaplikasikan VRP menggunakan metode ACO untuk menentukan rute yang optimal pada kegiatan inspeksi jembatan, dengan hasil terbukti dapat meminimumkan biaya inspeksi yang didalamnya termasuk biaya perjalanan. Terkait efisiensi kendaraan terlihat memiliki efisiensi yang tinggi (di atas 80 persen) dengan perbedaan secara keseluruhan tidak terlalu jauh. Hasil temuan penelitian ini menunjukkan bahwa rute usulan lebih baik dibandingkan dengan rute existing. Tabel perbandingan rute hasil temuan dan rute existing dapat dilihat pada Tabel 6. Sebagai penjelasan lebih lanjut dari Tabel 6 , titik 0 adalah depot/terminal yang merupakan lokasi perusahaan. Hasil optimasi mendapatkan selisih jarak total sebesar $36 \mathrm{~km}$ setiap siklus rute.

Tabel 6. Perbandingan jarak tempuh rute existing dan hasil temuan

\begin{tabular}{cccccc}
\hline \multicolumn{3}{c}{ Rute Existing } & & \multicolumn{3}{c}{ Rute Hasil Optimasi } \\
\hline Rute Urutan Lokasi & $\begin{array}{c}\text { Jarak } \\
(\mathrm{Km})\end{array}$ & $\begin{array}{c}\text { Efisiensi Loading } \\
\text { Kendaraan (\%) }\end{array}$ & Rute Urutan Lokasi & Jarak (Km) & $\begin{array}{c}\text { Efisiensi Loading } \\
\text { Kendaraan (\%) }\end{array}$ \\
\hline $0-5-6-7-0$ & 94.4 & 97.44 & $0-7-3-5-21-0$ & 90.4 & 96.28 \\
$0-2-9-10-3-4-0$ & 98.8 & 89.2 & $0-6-15-9-2-8-0$ & 102.3 & 94.96 \\
$0-12-13-14-16-21-0$ & 186.6 & 86.57 & $0-4-10-22-17-20-0$ & 148.3 & 97.11 \\
$0-15-17-18-20-22-0$ & 192.1 & 97.17 & $0-12-11-19-0$ & 96.85 & 96.33 \\
$0-11-19-8-0$ & 99.45 & 96.13 & $0-16-14-18-13-0$ & 197.5 & 81.82 \\
\hline Total Jarak & 671.35 & 93 & Total Jarak & 635.35 & 93 \\
\hline
\end{tabular}




\section{KESIMPULAN}

Penelitian ini menghasilkan lima rute optimal yang dapat diusulkan kepada perusahaan, pengurangan jarak tempuh kendaraan pengangkut sebanyak $36 \mathrm{~km} / \mathrm{hari}$, jika dibandingkan dengan rute yang berjalan saat ini. Penelitian selanjutnya diharapkan dapat berkembang dengan mempertimbangkan situasi permasalahan permintaan yang bersifat probabilistik, situasi loading dan unloading yang bersifat probabilistik, penggunaan berbagai jenis kendaraan, dan karakteristik lainnya yang relevan di dunia nyata. Selain itu, diharapkan dapat melakukan sejumlah eksperimen dengan mengubah jumlah lokasi yang dikunjungi untuk memeriksa kualitas solusi dan waktu komputasi dengan menggunakan metode ACO. Selain itu kualitas solusi dan waktu komputasi dengan metode ACO dapat dibandingkan dengan berbagai metode lainnya.

\section{DAFTAR PUSTAKA}

[1] A. Ahkamiraad and Y. Wang, "Capacitated and multiple cross-docked vehicle routing problem with pickup, delivery, and time windows," Comput. Ind. Eng., vol. 119, pp. 76-84, May 2018, doi: 10.1016/j.cie.2018.03.007.

[2] J. Pekar, I. Brezina, and Z. Cickova, "Synchronization of Capacitated Vehicle Routing Problem among Periods 1," Ekon. Cas., vol. 65, no. 1, pp. 66-78, 2017, available

at:

http://cejsh.icm.edu.pl/cejsh/element/bwm eta1.element.cejsh-8259290f-b6b0-43fd9c72-6daf6781c60d.

[3] L. Guimarães, P. Amorim, F. Sperandio, F. Moreira, and B. Almada-Lobo, "Annual Distribution Budget in the Beverage Industry: A Case Study," Interfaces (Providence)., vol. 44, no. 6, pp. 605-626, Dec. 2014, doi: 10.1287/inte.2014.0747.

[4] S. Rahman and Y.-C. Jim Wu, "Logistics outsourcing in China: the manufacturercum-supplier perspective," Supply Chain Manag. An Int. J., vol. 16, no. 6, pp. 462473, Sep. 2011, doi: 10.1108/13598541111171156.

[5] A. Hübl, H. Jodlbauer, and K. Altendorfer, "Influence of dispatching rules on average production lead time for multi-stage production systems," Int. J. Prod. Econ., vol. 144, no. 2, pp. 479-484, Aug. 2013, doi: 10.1016/j.jpe.2013.03.020.

[6] C.-K. Ting and X.-L. Liao, "The selective pickup and delivery problem: Formulation and a memetic algorithm," Int. J. Prod.
Econ., vol. 141, no. 1, pp. 199-211, Jan. 2013, doi: 10.1016/j.ijpe.2012.06.009.

[7] A. S. White and M. Censlive, "An alternative state-space representation for APVIOBPCS inventory systems," $J$. Manuf. Technol. Manag., vol. 24, no. 4, pp. 588-614, Apr. 2013, doi: 10.1108/17410381311327413.

[8] G. Guizzi, R. Revetria, D. Chiocca, and E. Romano, "A dynamic milk run in WEEE reverse logistics," Adv. Comput. Sci., pp. 478-484, 2012, available at: https://pdfs.semanticscholar.org/3768/d19 f732fe04493df8ffcf7c5d550850da169.pdf.

[9] O. A. W. Riyanto and B. Santosa, "ACOLS Algorithm for Solving No-wait Flow Shop Scheduling Problem," in International Conference on Soft Computing, Intelligence Systems, and Information Technology, Springer, 2015, pp. 89-97, doi: 10.1007/978-3-66246742-8_8.

[10] M. Dorigo and T. Stützle, "Ant Colony Optimization: Overview and Recent Advances," in Handbook of metaheuristics, Springer, 2019, pp. 311351, doi: 10.1007/978-3-319-91086-4_10.

[11] G. Fuellerer, K. F. Doerner, R. F. Hartl, and M. Iori, "Ant colony optimization for the two-dimensional loading vehicle routing problem," Comput. Oper. Res., vol. 36, no. 3, pp. 655-673, Mar. 2009, doi: 10.1016/j.cor.2007.10.021.

[12] B. Yu and Z. Z. Yang, "An ant colony optimization model: The period vehicle routing problem with time windows," Transp. Res. Part E Logist. Transp. Rev., vol. 47, no. 2, pp. 166-181, Mar. 2011, doi: 10.1016/j.tre.2010.09.010.

[13] A. E. Rizzoli, R. Montemanni, E. Lucibello, and L. M. Gambardella, "Ant colony optimization for real-world vehicle routing problems," Swarm Intell., vol. 1, no. 2, pp. 135-151, Nov. 2007, doi: 10.1007/s11721-007-0005-X.

[14] S.-H. Xu, J.-P. Liu, F.-H. Zhang, L. Wang, and L.-J. Sun, "A Combination of Genetic Algorithm and Particle Swarm Optimization for Vehicle Routing Problem with Time Windows," Sensors, vol. 15, no. 9, pp. 21033-21053, Aug. 2015, doi: 10.3390/s150921033.

[15] S. N. Kumar and R. Panneerselvam, "A survey on the vehicle routing problem and its variants," Intell. Inf. Manag., vol. 4, no. 03, pp. 66-74, 2012, available at: https://pdfs.semanticscholar.org/ea41/6f2 9b6aa4bb17abddfbb82272e2cb30d6af3.p 
df.

[16] M. Dorigo and C. Blum, "Ant colony optimization theory: A survey," Theor. Comput. Sci., vol. 344, no. 2-3, pp. 243278, Nov. 2005, doi: 10.1016/j.tcs.2005.05.020.

[17] U. Teschemacher and G. Reinhart, "Ant Colony Optimization Algorithms to Enable Dynamic Milkrun Logistics," Procedia CIRP, vol. 63, pp. 762-767, 2017, doi: 10.1016/j.procir.2017.03.125.

[18] S. Gao, Y. Wang, J. Cheng, Y. Inazumi, and Z. Tang, "Ant colony optimization with clustering for solving the dynamic location routing problem," Appl. Math. Comput., vol. 285, pp. 149-173, Jul. 2016, doi: 10.1016/j.amc.2016.03.035.

[19] B. Yao, Q. Yan, M. Zhang, and Y. Yang, "Improved artificial bee colony algorithm for vehicle routing problem with time windows," PLoS One, vol. 12, no. 9, pp. 1-18, Sep. 2017, doi: 10.1371/journal.pone.0181275.

[20] S.-H. Huang, Y.-H. Huang, C. A. Blazquez, and G. Paredes-Belmar, "Application of the ant colony optimization in the resolution of the bridge inspection routing problem," Appl. Soft Comput., vol. 65, pp. 443-461, Apr. 2018, doi: 10.1016/j.asoc.2018.01.034

[21] S. Mazzeo and I. Loiseau, "An Ant Colony Algorithm for the Capacitated Vehicle Routing," Electron. Notes Discret. Math., vol. 18, pp. 181-186, Dec. 2004, doi: 10.1016/j.endm.2004.06.029.

[22] N. Rouky, J. Boukachour, D. Boudebous, and A. E. H. Alaoui, "A Robust Metaheuristic for the Rail Shuttle Routing Problem with Uncertainty: A Real Case Study in the Le Havre Port," Asian J. Shipp. Logist., vol. 34, no. 2, pp. 171-187, Jun. 2018, doi: 10.1016/j.ajsl.2018.06.014. 